\title{
A Geospatial Approach in the Impact Assessment of Tannery Industries on Upper Palar Basin
}

\author{
Ms. Karthika Krishnan and V. Emayavaramban \\ Department of Geography, Madurai Kamaraj University, India-625021
}

\begin{abstract}
Environmental degradation and crumbling ecosystem that the human species has wrought upon the mother earth is fast escalating throughout the world and is currently the most debated topic globally. Thanks to the name of economic development, river basins in our ecosystem are vanishing and are under constant threat of being flushed out of their existence. Malattar river sub basin (Upper Palar basin) is a good example of how in the name of economic growth, an environment can be ruined totally. In such a context, an investigation on impact assessment of environment on Malattar river sub basin has been made using Geospatial techniques. The discharging of untreated effluents from tannery industries has turned the upper Palar region to be the worst affected casualty in terms of environmental degradation. The present paper attempts to analyse the effectiveness of GIS, GPS and ERDAS tools to find out the degree of environmental damage undergone by the basin over the past 40 years. The results have been generated through maps prepared from toposheet, landsat and Google earth imageries. The Geomatic study that brought the results shows that the basin is under a high rate of irreversible degradation. The dominancy of tannery industries is highly alarming that, there is a mushrooming of 154.54 percent increase in overall number of tannery units in the study area during the last 40 years, due to which the land use and land cover of the region has changed drastically. Finally it has been analysed that Geospatial technique is an effective measurement for monitoring EIA and environmental degradation process thereby generating qualitative predictions and solutions to overcome the impacts through sustainable development.
\end{abstract}

Keywords: Geomatics, Tannery, Degradation, GIS, GPS, ERDAS and EIA.

\section{Introduction}

The environment as an issue is ubiquitous in the world we live in. There has been a constant explosion of work that reflects on the reasons for and responses to ecological dilemmas. An Environmental Impact Assessment (EIA) is a tool used to identify, predict, mitigate and analyse the environmental, social and economic implications of any developmental project on a biophysical environment (International Association for Impact Assessment, 1999). The directives of EIA aim to provide a high level of protection to the environment and to contribute to the integration of environmental consideration into the preparation of projects, plans and programmes with a view to reduce their environmental impacts in a long run.

The last decade and a half in particular, is facing constant threat of ecological disintegration (Ranagarajan, 2007). In the name of economic development, river basins in our ecosystem are vanishing and are under constant threat of being flushed out of their existence. In such a context, an investigation with the help of geospatial technology on impact assessment of environment on Malattar river sub basin (Upper Palar basin) for 40 years has been made.

\section{Geospatial Technology for Environmental Impact Assessment}

In the era of quantitative revolution, information technology has strongly developed with diverse application. As part of this revolution, Geospatial technology emerged as a pioneering technology of great significance and serve as a powerful aid in monitoring environment and managing the natural resources. Geospatial technology is a rapidly expanding multidisciplinary field that involves a suite of three technologies; Geographic Information System (GIS), Global Positioning System (GPS) and Remote Sensing (RS); that help in capturing, storing, processing, displaying and disseminating information tied to a specific location. Now a day, Geospatial technology has become a key Science for decision support of sustainable development, impact assessment and management of environmental resources (Noor Mohammad et al., 2007).

This paper discusses the application of GIS, GPS and ERDAS tools in mapping and monitoring the impact assessment of environment on river sub basin. The combined use of Geographical Information System (GIS) and Digital Image Processing (DIP) provide better prospects of applying geomatics for Environmental Impact Assessment and forecasting the threats of environmental degradation over wider areas with limited time span. Global Positioning Systems (GPS) provides a 3 dimensional geographical positions 24 hour per day basis of any spatial unit with exact precision, thus contributing greatly in the field of spatial mapping in EIA. In such 
a context, a Geospatial technique based visualization and analysis of EIA has been attempted on Malattar river sub basin.

\section{Problem Definition}

Environmental questions, whether of safety and risks, of resource development or access, of pollution or extinction of biodiversity, are more crucial today than ever before. There have been attempts to grapple impact assessment on river basin in the past, but these often suffer setbacks due to lack of various long term data. Hence there is an emerging significance to build an EIA for river basins, as these basins are undergoing a high degree of degradation due to various human developmental projects. In 1994, a far reaching notification by the Ministry of Environment and Forests (MoEF) made it obligatory for almost all developmental and industrial activities in and around river basins to conduct EIA studies. The present sub basin, Malattar Basin is under constant threat of degradation as a result of discharging of untreated effluents from tannery industries that have mushroomed throughout the basin. The casualty is such alarming that, it makes necessary to build EIA within a specific period of time, so as to formulate effective strategies to reduce the potential impacts so as to make our environment safe and secure.

\section{Study Area}

The present field of investigation is at Malattar River Sub basin, a tributary of Palar Basin. Geographically, the study area lies between $12^{\circ} 50^{\prime} \mathrm{N}$ to $13^{\circ} 10^{\prime} \mathrm{N}$ latitude and $78^{\circ} 20^{\prime} \mathrm{E}$ to $78^{\circ} 45^{\prime} \mathrm{E}$ longitude (Fig: 4.1), covering an area of about 1011.36 sq. km. The basin lies in the administrative division of Karnataka, Andhra Pradesh and Tamil Nadu states. Lithologically, Malattar River Sub-basin is mainly underline by dharwar carton, especially that of charnockites and granatoid gneiss. The region falls under semi-arid tropical monsoon climate with high continentality. Land use types are generally governed by forest vegetation, agricultural lands, open scrubs and barren areas.

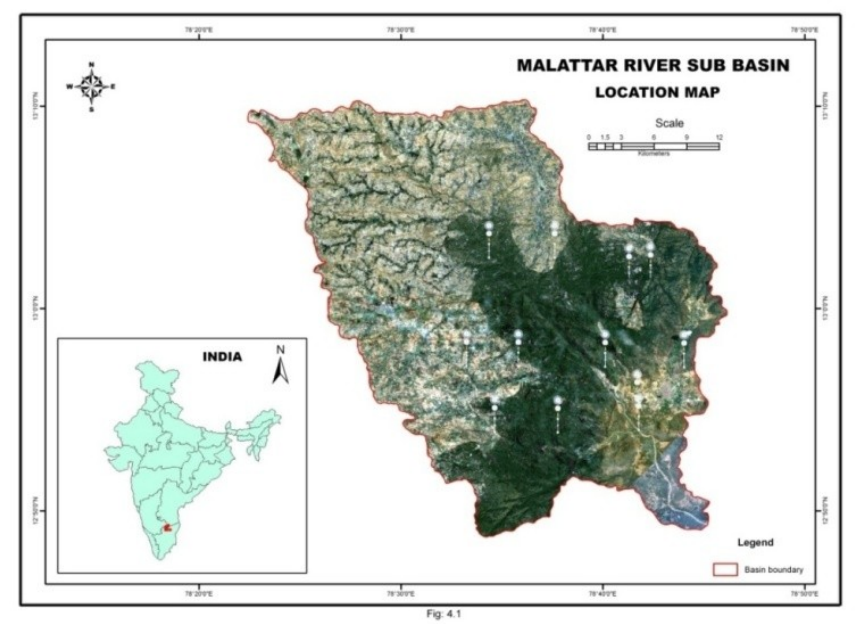

\section{Aim \& Objectives}

The main aim of the present study is to analyze and investigate the effectiveness of Geospatial techniques in assessing and monitoring the impact of human interference on a river basin environment. The framed objectives for the given paper are:

1. To investigate potential environmental impacts due to unscientific and haphazard manner of tanning industries activities in the sub basin.

2. To analyse the temporal variations and dynamics in the sub basin as a result of human interference in the name of development from 1972 to 2011.

3. To assess the temporal land use and land cover changes caused as a result of environmental degradation due to various projects.

4. The study also involves in finding a feasible suggestions and strategic measures of monitoring and conservation to reduce the environmental degradation faced by the sub basin.

\section{Methodology}

An assessment of the impact of effluent discharge of tanneries on various components of a river sub basin environment is a difficult process since the adverse effects can be witnessed only after a long run. Hence a 
method has been adopted to analyze the existing reality of environment and some selected case analysis has been made to attain the objective of the study.

The entire sub basin has been captured from survey of India toposheet of 1:50,000 scale, surveyed in the year 1971 and delineated with the help of Arc GIS software. Google Earth imagery of the study area for the year 2011 has been captured and geo referenced with toposheet. Then a GPS survey has been conducted to locate the thrust areas of tannery industries. The coordinates of these vulnerable sites have been transferred from GPS to Google imagery and areas have been plotted and calculated. The EIA of illegal tannery industry activities on changes in the land use / land cover (Fig: 5.1) of the study region has been generated using Landsat TM imageries of 1972 and 2011 with $30 \mathrm{~m}$ resolution. These images are then processed and classified on ERDAS image processing software. Finally the maps are generated on Arc GIS 9.3, and then interpretation and analysis have been made for an immediate action to reduce the impact.

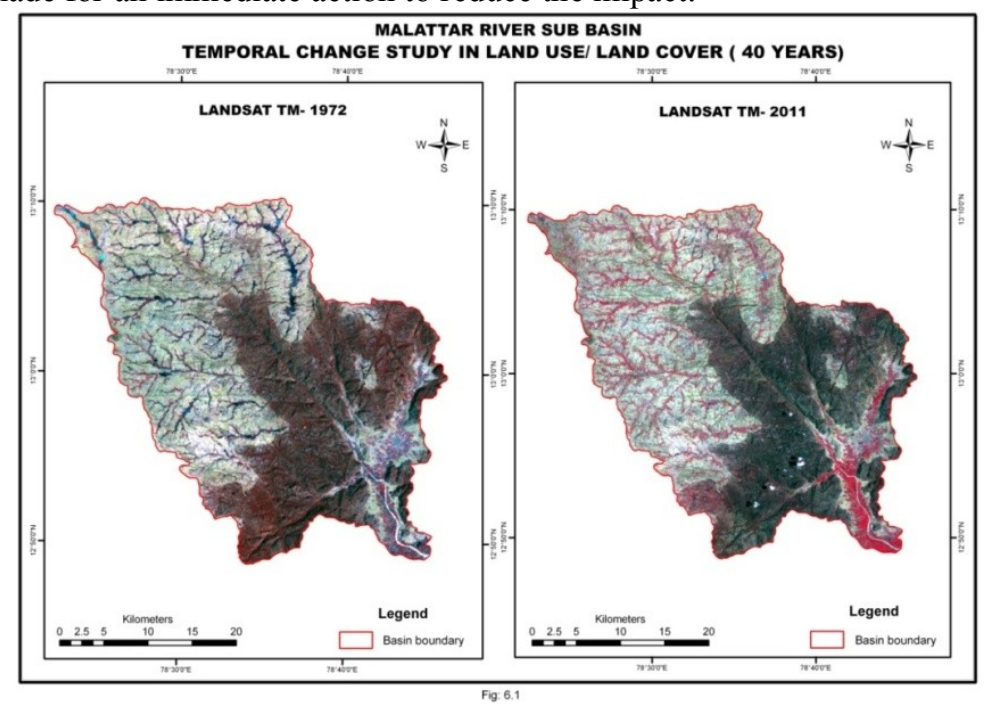

\section{VII.Results and Discussion}

Metal contamination is one of the major environmental issues in many countries as these contaminants generally come from various industries like leather, agriculture and textiles industries. Leather tanning industries have cropped up in India over the past 4 decades like mushrooms. Palar river basin is the hub of tannery industries in India. Nearly 70 percent of India's total export of leather and leather products comes from tanneries in Palar basin region. Malattar sub basin that comprises of Upper Palar basin is one of the prominent river sub basin associated with leather tanning industries since 1950s. Malattar basin is a highly desirable location for tanning units as a result of proximity to tanning materials, which grew abundantly in the nearby mountain areas, availability of river water and its quality, and proximity to the port city of Chennai. Growth of tannery industries is linearly associated with the waste it discharged. Tannery waste is highly characterized by high BOD, COD, residual dyes, high $\mathrm{pH}$ and sulphuric acid, and high amount of dissolved salts and metals especially that of chromium.

The major findings of the geospatial techniques on basin shows that, Malattar basin has been critically affected by pollution caused by untreated discharge of effluents from tannery industries over the past 40 years. The result throws light that, there is an unprecedented rise of 154.54 percent increase (Table 6.1) in the overall number of tannery units in the study area from 1972 to 2011, due to which land use and land cover of the region has changed drastically (Table 6.2). Considering the case of tannery units, presently 28 units are operating in 2011 in the sub basin as against 11 units (Fig: 6.1) in 1972. Observations that made on the land use / land cover studies (Fig: 6.2) reveal that the area under forest has reduced from 404.5 sq.km to 389.49 sq.km within last 40 years. Similarly is the case with cultivation, area of water bodies, agriculture and open scrubs. The degradation of the sub basin can be clearly seen through a high increase in agricultural fallow land from 123.3 sq.km in 1972 to 209.99 sq.km in 2011. There has only been a slight increase in area under settlements which is of $0.36 \mathrm{sq} . \mathrm{km}$ due to inhospitable condition of the sub basin as a result of environmental degradation caused by these industrial activities. Many of the settlements near to river course have been abandoned by the people due to high pollution and moved to higher areas.

Table: 6.1

\begin{tabular}{|l|c|c|c|}
\hline Anthropogenic Activity & \multicolumn{2}{|c|}{ Distribution of Tannery Industries (no.) } & $\begin{array}{l}\text { Percentage change over 40 years } \\
\text { (\%) }\end{array}$ \\
\hline \multirow{2}{*}{ Tannery industrial plants } & $\mathbf{1 9 7 2}$ & $\mathbf{2 0 1 1}$ & 154.54 \\
\hline & 11 & 28 & $16 \mid$ Page \\
\hline \multicolumn{2}{|r|}{}
\end{tabular}




\section{Impact of tannery effluents discharge}

Scientific studies have found that the discharging of highly toxic effluents that percolate into ground surface for a prolonged period would severely affect not only the ground water table of the locality, but also impair the water quality. Contamination of ground water in Malattar basin has thus caused water scarcity for agriculture as well as for domestic purposes. It has been found that, around $2.07 \mathrm{sq} . \mathrm{km}$ of area under fresh water tanks and ponds (Table 6.3) have already been lost due to high contamination (Fig: 6.3).

The quality of water has degraded so much that the crops no longer grow when irrigated by the contaminated water due to clogging of salts at the roots. The crops that were extensively grown in Malattar basin such as Paddy, groundnut and coconut, 40 years ago, are no longer cultivated now there by reducing the agricultural scrub area from 345.8 sq.km in 1972 to 299.002 sq.km in 2011 (Fig: 6.4).

Causes heavy contamination of surface water. An estimated 40 million liters of untreated effluents are discharged daily into rivers and water bodies, which in turn increase the acidity, hardness or salinity of the streams and even change the colour of water. Total Dissolved Salts (TDS) in some water bodies in the basin is as high as $1700 \mathrm{mg} / \mathrm{l}$.

During the past 40 years, effluent discharge has lead to over growth of aquatic weeds thereby choking the aquatic life. Fishes and other aquatic life have been detrimentally affected.
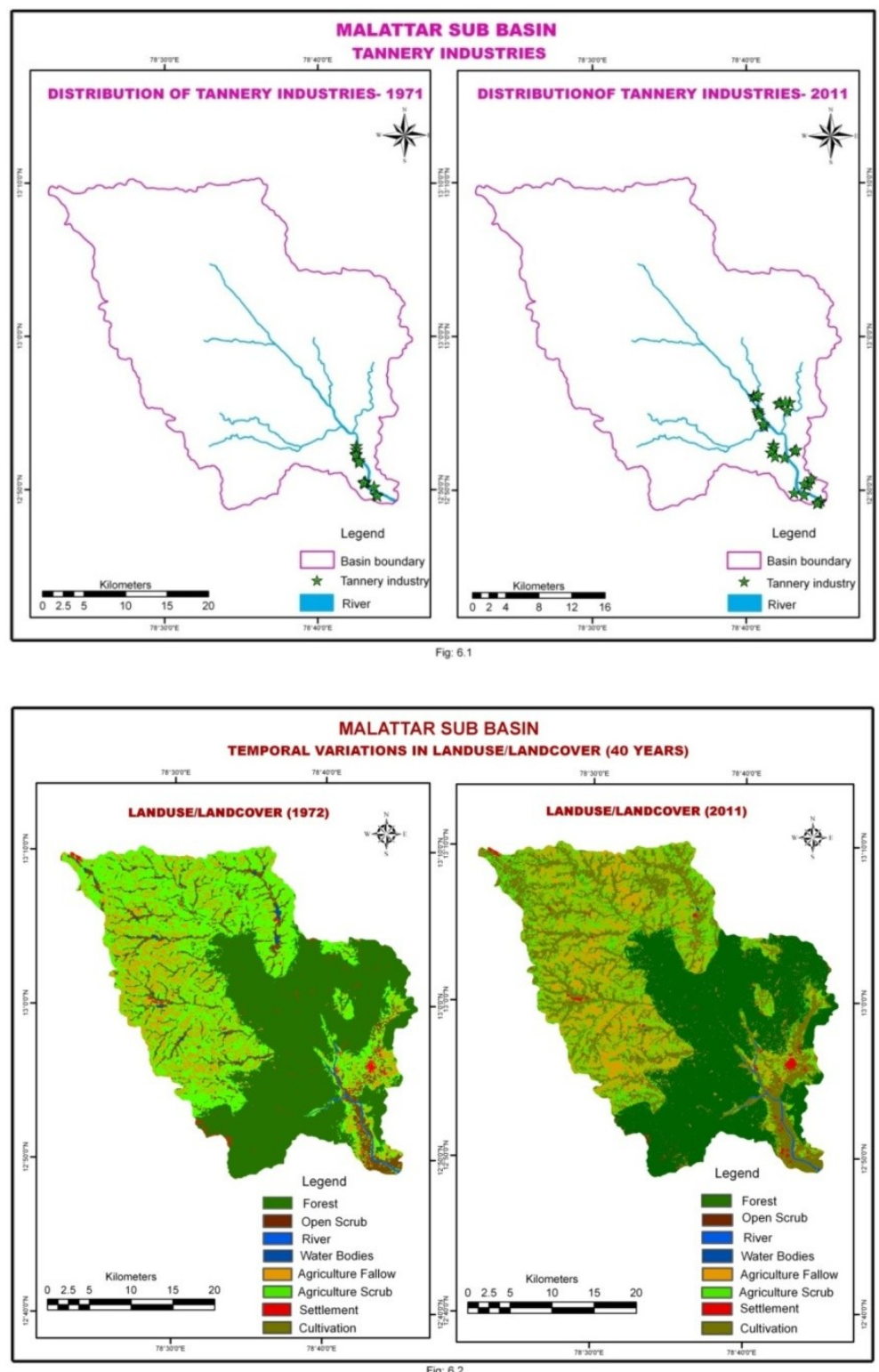
Table: 6.2

\begin{tabular}{|l|c|c|}
\hline \multirow{2}{*}{ Land use/ Land cover } & \multicolumn{2}{|c|}{ Change in Areal Distribution over 40 years $\left.\mathbf{( k m}^{\mathbf{2}}\right)$} \\
\cline { 2 - 3 } & $\mathbf{1 9 7 2}$ & $\mathbf{2 0 1 1}$ \\
\hline Forest & 404.55 & 389.49 \\
\hline Open scrub & 4.98 & 4.49 \\
\hline River & 4.67 & 4.37 \\
\hline Water bodies & 17.76 & 15.05 \\
\hline Agriculture fallow & 123.26 & 209.99 \\
\hline Agriculture scrub & 345.8 & 299.002 \\
\hline Settlement & 5.99 & 6.35 \\
\hline Cultivation & 104.49 & 827.67 \\
\hline Total & 1011.36 & 1011.36 \\
\hline
\end{tabular}

Table: 6.3

\begin{tabular}{|c|c|c|c|}
\hline \multirow{2}{*}{ Degraded Parameter } & \multicolumn{2}{|c|}{ Area under Fresh water Tanks \& Ponds $\left(\mathbf{k m}^{\mathbf{2}}\right)$} & $\begin{array}{l}\text { Percentage change over 40 } \\
\text { years (\%) }\end{array}$ \\
\hline \multirow{2}{*}{ Tanks \& Ponds } & $\mathbf{1 9 7 2}$ & $\mathbf{2 0 1 1}$ & \multirow{2}{*}{12.06} \\
\cline { 2 - 3 } & 17.141 & 15.074 & \\
\hline
\end{tabular}

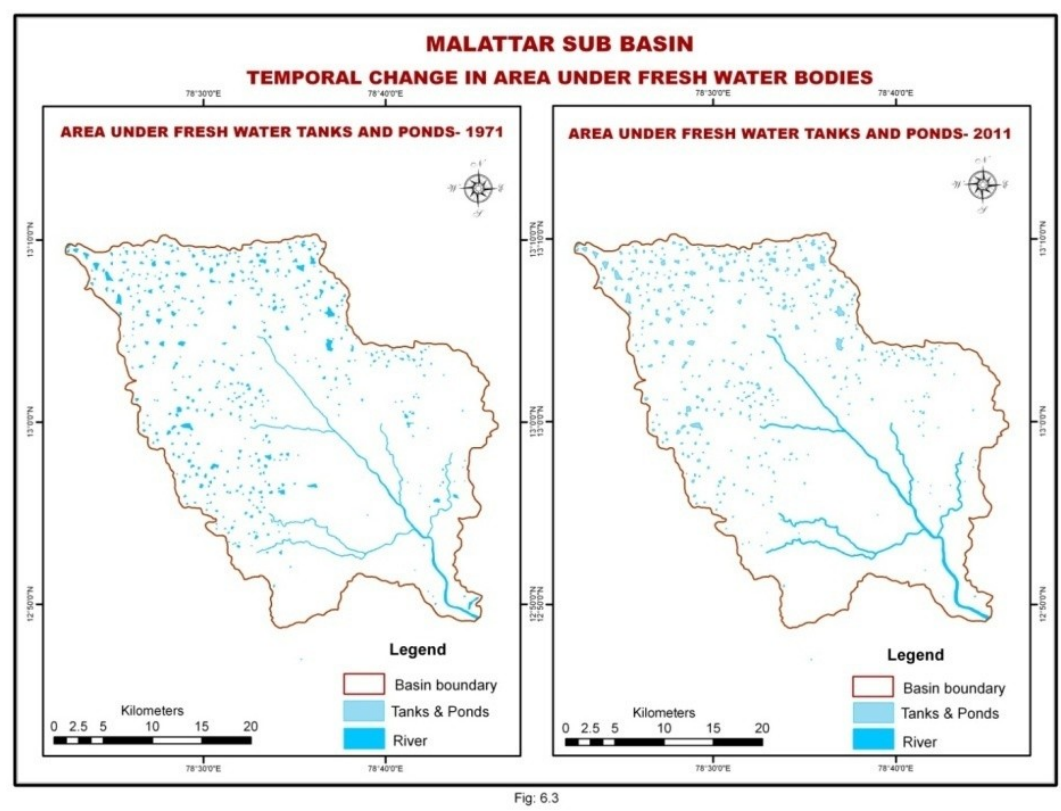

High amount of TDS trivalent and hexavalent chromium in land and ground water would result in land and soil degradation.

> The effect of chromium sulphate on human body is potentially lethal. Consuming of such contaminated water is responsible for many epidemics (Vishwajith Gupta, 2005). It has already been reported that a high percentage of population in the basin is suffering from skin disease, stomach ailments, and problems with respiratory and immune system, kidney and liver problems and lung cancer (K. Sundaret al., 2010).

\section{Suggestions And Recommendations}

The complex ecological impact caused by the past environmental degradation due to various anthropogenic activities that conflict with local and regional development necessitates a well defined management scheme to optimize use of river as a resource and secure its long term sustainability. Considering the degree of degradation caused by the effluents of tannery industries, no industrial scenario may be opted in basin zones. However since the level of development should get proceed in present era, some suggestions and recommendations have been made to recover the sub basin from the impact of environmental degradation. It should be made mandatory to conduct an Environmental impact Assessment in all river basins for all developmental activities involving in investments of Rs. 50 crore and above. In case of river pollution by tannery industries, there should be a strong advocacy of closing those tannery units that strictly violate the rule of installation of pollution treatment plants. Since there is no alternate source of fresh water in the basin, the only way that could remove salts from water is that of desalination process (ShreyKankariaet al., 2011). A compulsory environmental audit with the help of GPS and radars could be a possible solution to monitor the level of environmental degradation in those areas that got clearance from government for these development 
projects. A broad geospatial multi disciplinary study and monitoring approach would provide a solid base for a long term management plan for the river basin recovery.

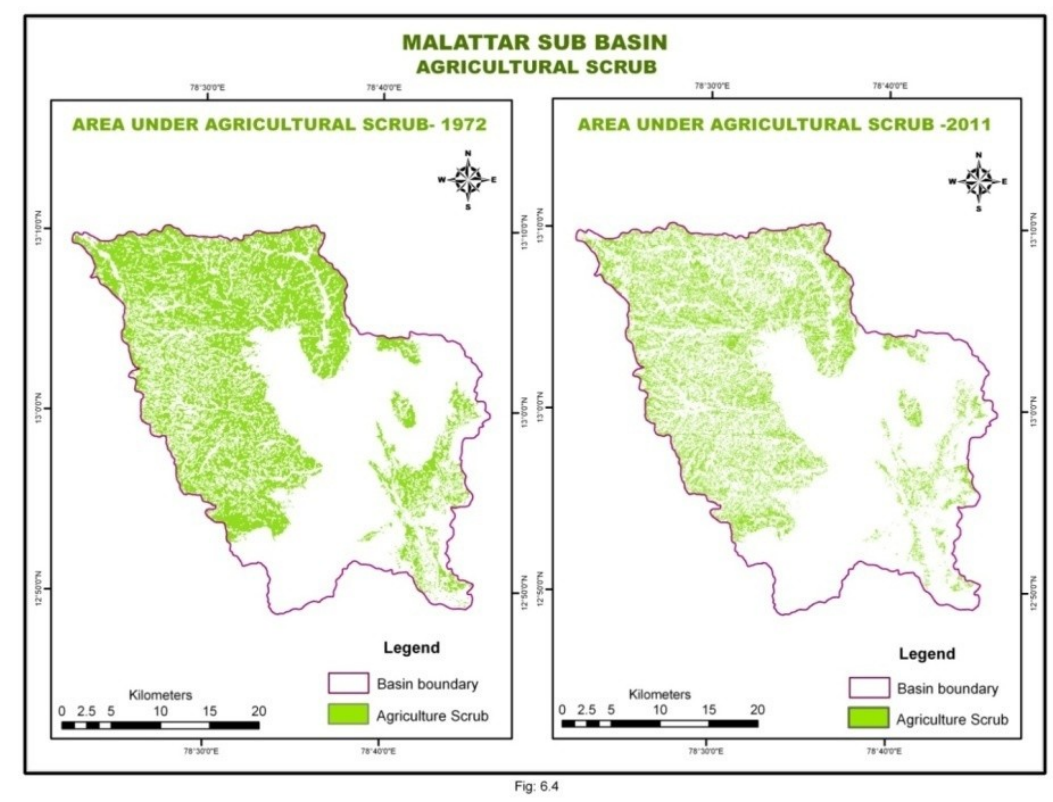

IX. Conclusion

Recognizing that anthropogenic actions towards nature and each other are the source of growing damage to environment and resources, there is a growing need for sustainable development to make earth secure and hospitable. Now a day, there is an ever increasing demand to build EIA for a region. Any developmental endeavor requires an EIA as it conducts detailed assessment on problems, conflicts and natural resource constraints and to reduce their impacts in a long run. The Present paper attempts to integrate three techniques; Remote sensing, GIS and GPS to predict EIA and analyze the temporal changes taken place in Malattar sub basin on account of various developmental activities. EIA carried out with the help of geospatial techniques project that tannery effluent discharge have affected not only Malattar river ecosystem, but also degraded the economic and social quality of all the beings associated with the basin. Satellite remote sensing has been effectively used for land use mapping and monitoring environmental degradation process there by supporting a system for sustainable development. Finally, it has been concluded that the application geospatial technology is an effective measurement for monitoring the environment and its environmental degradation process and provides several capabilities by generating qualitative predictions and suggestions to overcome the impacts through sustainable action.

\section{References:}

[1]. International Association for Impact Assessment, Principle of Environmental Impact Assessment Best Practice, 1999

[2]. Noor Mohammad, Singh,R.B.,Spatial information technology for natural resources management, 2007, pp. 9-11.

[3]. Ranagarajan Mahesh, Environmental issues in India,2007, pp. 10 -12 and 263-268.

[4]. ShreyKankaria, AnushaAndukuri, Hemamailini C.G., Krishnaveni M., Impact of tannery effluent on ground water and agriculture with a remedial measure, ICCEBS, 2011, pp. 1-6.

[5]. Sundar K., Vidya R., Amitava Mukherjee and Chandrasekaran, N., High chromium tolerant bacterial strains from Palar river basin: Impact of tannery pollution, Research Journal of Environmental and Earth Science, Vol. 2, 2010, pp. 112-117.

[6]. Gupta Vishwajith, Environment: Geogenic factors, human health and pollution; Part: 1, 2005, pp.1-9. 